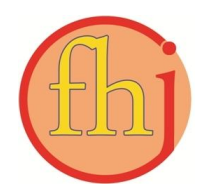

Faletehan Health Journal, 6 (2) (2019) 69-74

www. journal.Ippm-stikesfa.ac.id/ojs/index.php/FHJ

ISSN 2088-673X | e-ISSN 2597-8667

\title{
Analisis Faktor yang Berhubungan dengan Respon Keluarga Penderita Gangguan Jiwa Rawat Jalan di Rumah Sakit Jiwa Provinsi Sulawesi Tenggara
}

\author{
La Ode Alifariki ${ }^{*}$ \\ ${ }^{1}$ Konsentrasi Keperawatan Fakultas Kedokteran Universitas Halu Oleo, Kendari, Indonesia \\ *Corresponding Author: ners_riki@yahoo.co.id
}

\begin{abstract}
Abstrak
Penderita gangguan jiwasering mendapatkan stigma dandiskriminasi yang lebih besar darimasyarakat disekitarnyadibandingkan individu yangmenderita penyakit medis lainnya.Tidak hanya menimbulkankonsekuensi negatif terhadappenderitanya tetapi juga bagianggota keluarga, meliputi sikappenolakan, penyangkalan, dandisisihkan. Penelitian ini bertujuan untuk mengetahui faktor yang berhubungan dengan respon keluarga penderita gangguan jiwa. Jenis penelitian ini adalah analitik dengan menggunakan desain cross sectional dengan jumlah sampel sebanyak 43 responden. Sampel ditentukan menggunakan purposive sampling. Pengumpulan data menggunakan questioner, data dianalisis dengan menggunakan Chi Square (X2). Hasil penelitian menunjukkan bahwa ada hubungan lemah antara pengetahuan dengan responkeluarga penderita gangguan jiwa rawat jalan (X2hit $=7,467$, phi $=0,477$ ); ada hubungan sedang antara struktur keluarga dengan responkeluarga penderita gangguan jiwa rawat jalan (X2hit = 10,356, phi =0,557); ada hubungan kuat antara sistem pendukung dengan responkeluarga penderita gangguan jiwa rawat jalan (X2hit $=16,320$, phi $=0,675$ ); dan ada hubungan kuat antara sumber daya keluarga dengan responkeluarga penderita gangguan jiwa rawat jalan (X2hit $=10,689$, phi $=0,557$ ). Penelitian ini dapat disimpulkan bahwa respon keluarga terhadap penderita gangguan jiwa berhubungan dengan pengetahuan, struktur keluarga, sistem pendukung dan sumber daya keluarga.
\end{abstract}

Kata Kunci: Gangguan Jiwa, Respon Keluarga

\begin{abstract}
People with mental disorders often get greater stigma and discrimination from their respective communities. It does not only have negative consequences for sufferers, but also for family members, includes the rejection, denial and exclusion. This study aims to determine the factors assosciated with the family response of people wit mental health disorder. This research is analytic using a cross sectional design with a total sample of 43 respondents. The sample is determined using purposive sampling. The technique of collecting data using questionnaires and data were analyzed with chi square (X2) test. The results showed that there was a weak relationship between knowledge and family responses of outpatients with mental disorders $(X 2 h i t=7.467$, phi $=0.477)$, there was a moderate relationship between family structures and responses of street mental health nurses ( $X 2 \mathrm{hit}=10.356$, phi $=0.557$ ), there is a strong relationship between the support system with outpatient emergency response families (X2hit $=16,320$, phi $=0,675$ ), There is a strong relationship between family resources and the outpatient family response $(X 2 h i t=10,689$, phi $=$ 0,557). This study can conclude that family respon to mental problems are related to knowledge, family structure, support systems and family resources.
\end{abstract}

Keywords: M ental Disorders, Family; Inpatient, Response 


\section{Pendahuluan}

Fenomena gangguan jiwapada saat ini mengalami peningkatan yang sangat signifikan, dan setiaptahun di berbagai belahan dunia jumlah penderita gangguan jiwa bertambah. Ada data yang menunjukkan tingkat sosial ekonomi memiliki efek pada kesehatan jiwa, dan terutama berdampak pada penyakit depresi, seperti kurangnya dukungan dari keluarga inti, banyak anggota keluarga yang mengalami gangguan jiwa justru diasingkan oleh keluarga ataupun masyarakat (Basford, 2006). Pada Era Globalisasi dan persaingan bebas ini kecenderungan terhadap peningkatan gangguan jiwa semakin besar, hal ini disebabkan karena stresor dalam kehidupan semakin kompleks. Peristiwa kehidupan yang penuh tekanan seperti kehilangan orang yang dicintai, putusnya hubungan social pengangguran, masalah dalam pernikahan, kesulitan ekonomi, tekanan di pekerjaan dan diskriminasi meningkatkan resiko penderita gangguan jiwa (Suliswati,2005).

Gangguan jiwa adalah gangguan dalam cara berpikir (cognitive), kemauan (volition), emosi (affective),dan tindakan (psychomotor). Kumpulan dari keadaan-keadaan yang tidak normal, baik yang berhubungan dengan fisik, maupun dengan mental. Keabnormalan tersebut yaitu: gangguan jiwa neurosa dansakit jiwa (psikosa). Keabnormalan terlihat dalam berbagai macam gejala yang terpenting diantaranya adalah: ketegangan (tension), rasaputus asa dan murung, gelisah, cemas, perbuatan-perbuatan yang terpaksa (convulsive), hysteria, rasalemah, tidak mampu mencapaitujuan, takut, pikiran-pikiran buruk (Yosep, 2007).

Penderita gangguan jiwa sering mendapatkan stigma dan diskriminasi yang lebih besar dari masyarakat disekitarnya dibandingkan individu yang menderita penyakit medis lainnya.Tidak hanya menimbulkan konsekuensi negatif terhadap penderitanya tetapi juga bagianggota keluarga, meliputi sikap penolakan, penyangkalan, dan disisihkan. Penderita gangguan jiwa mempunyai resiko tinggi terhadap pelanggaran hak asasi manusia (Priyanto, 2007). Mereka sering sekali disebut sebagai orang gila (insanity atau madness). Perlakuan ini disebabkan karena ketidaktahuan atau pengertian yang salah dari keluarga atau anggota masyarakat mengenai gangguan jiwa. Gangguan jiwa dapat mempengaruhi fungsi kehidupan seseorang. Aktivitas, kehidupan sosial, ritme pekerjaan, serta hubungan dengan keluarga jadi terganggu karena gejala ansietas, depresi, dan psikosis. Seseorang dengan gangguan jiwa apapun harus segera mendapatkan pengobatan. Keterlambatan pengobatan akan semakin merugikan penderita, keluarga dan masyarakat (Yosep, 2010).

Menurut WorldHealth Organization (WHO), masalah gangguan jiwa di seluruh dunia sudah menjadi masalah yang sangat serius. WHO menyatakan paling tidak ada 1 dari 4 orang di dunia mengalami masalah mental, diperkirakan ada sekitar 450 jutaorang di dunia yang mengalami gangguan kesehatan jiwa. Perkiraan oleh WHO menunjukkan bahwa 154 juta orang secara global mengalami depresi dan 25 juta orang menderita skizofrenia, 15 juta orang berada dibawah pengaruh penyalahgunaan zat terlarang, 50 juta orang menderita epilepsi dan sekitar 877.000 orang meninggal karena bunuh diri tiap tahunnya. Di Indonesia, data hasil survey kesehatan tahun 2013 menunjukkan bahwa prevalensi gangguan mental emosional pada penduduk $\geq 15$ tahun terbanyak adalah di Provinsi Sulawesi Tengah yaitu 12,3\%. Pada tahun 2018 terjadi peningkatan menjadi $19,8 \%$.

Pengetahuan keluarga mengenai kesehatan mental merupakan awal usahadalam memberikan iklim yang kondusif bagi anggota keluarganya. Keluarga selain dapat meningkatkan dan mempertahankan kesehatan mental anggota keluarganya, juga dapat menjadi sumber problem bagi anggota keluarga yang mengalami ketidakstabilan mental sebagai akibat minimnya pengetahuan mengenai persoalan kejiwaan keluarganya (Notosoedirdjo \& Latipun, 2005). Berdasarkan hasil penelitian Kartiko (2009), menunjukkan bahwa dari60 responden, sebagian besar $(70 \%)$ responden dengan skizofrenia yang menjalani rawat inap di Rumah Sakit Jiwa Daerah Surakarta kurang mendapatkan dukungan yang memadai dan pengetahuan keluarga yang kurang baik. Hal tersebut mengakibatkan proses perawatan pasien kurang optimal.

Berdasarkan data Rumah Sakit Jiwa Provinsi Sulawesi Tenggara pada tahun 2016, jumlah pasien rawat jalan yang menderita skizofrenia, gangguan skizotipal/psikotik akut dan sementara sebanyak 3.451 orang, gangguan depresif atau depresif berulang, gangguan mood sebanyak 709 
Faletehan Health Journal, 6 (2) (2019) 69-74

www. journal.Ippm-stikesfa.ac.id/ojs/index.php/FHJ

ISSN 2088-673X | 2597-8667

orang, gangguan anxietas fobik dan anxientas lainnya sebanyak 640 orang, hipertensi ensensial sebanyak 366 orang, penderita stroke 340 orang, penderita depresif gangguan cemas sebanyak 322 orang, penderita reaksi terhadap stres berat dan gangguan penyesuaian sebanyak 314 orang, epilepsi sebanyak 285 orang, gangguan saraf dan radiks/pleksus saraf sebanyak 281 orang, penyakit pulpa dan periapikal sebanyak 268 orang. Pada tahun 2017, jumlah pasien tertinggi adalah penderita skizofrenia, gangguan skizotipal, psikotik akut dan sementara yakni 868 orang, menyusul pasien episode depresif, gangguan depresif berulang, gangguan suasana perasaan yakni sebanyak 20 orang dan paling rendah adalah pasien gangguan anxietas fobik dan epilepsi masing-masing sebanyak 1 orang (Profil RSJ Provinsi Sulawesi Tenggara, 2017).

Berdasarkan survey danwawancara yang dilakukan terhadap 10 orang keluarga yang berkunjung pada Januari 2018, enam orang mengatakan penderita gangguan jiwa adalah orang dengan gangguan jiwa yang harus dihindari karena mereka berbahaya bagi orang lain dan bias mengamuk kapan saja dengan melempari barangbarang dan menyakiti warga, 3 orang mengatakan takut kepada penderita gangguan jiwa karena anak-anak mereka yang bermain sering diganggu dan kadang-kadang berkatakasar serta jorok yang tidak baik bagi anak-anak, 1 orang mengatakan orang dengan gangguan jiwa sebenarnya jangan dimusuhi karena mereka juga manusia, tetapi mereka hanya mengalami gangguan stress pada dirinya, penderita gangguan jiwa dan keluarganya sering dicemooh bahkan dikucilkan oleh masyarakat. Adanya persepsi bahwa kegilaan adalah aib menyebabkan orang dengan gangguan jiwa yang dianggap sembuh oleh dokter di rumah sakit jiwa tetap tidak dapat dipulangkan karena keluarga dan masyarakat tidak menginginkannya kembali. Hasil wawancara menunjukkan bahwa kurangnya sistem pendukung keluarga klien jiwa yang menunjang perawatan klien jiwa.

\section{Metode Penelitian}

Penelitian ini merupakan penelitian analitik observasional dengan menggunakan pendekatan cross sectional. Sampel dalam penelitian ini adalah keluarga yang berkunjung ke Rumah Sakit Jiwa Provinsi Sulawesi Tenggara dengan jumlah 43 responden yang ditentukan secara purposive sampling dengan kriteria inklusi sebagai berikut: keluarga yang mempunyai anggota keluarga rawat jalan, kooperatif, dan anggota keluarga yang sebelumnya sudah pernah melakukan kunjungan. Pengumpulan data primer dilakukan melalui wawancara dengan menggunakan kuesioner yang telah melalui uji validitas dan reliabilitas. Analisis data penelitian menggukana uji Chi Square pada derajat kemaknaan $95 \%$.

\section{Hasil dan Pembahasan}

Hasil penelitian akan disajikan dalam bentuk tabel gabungan variabel penelitian yakni hasil analisis deskripsi dan inferensial antar variabel. Adapun hasil penelitian ini dapat dilihat pada tabel berikut:

Tabel 1. Faktor-faktor yang Berhubungan dengan Respon Keluarga Pasien Rawat Jalan di RSJ Propinsi Sulawesi Tenggara

\begin{tabular}{|c|c|c|c|c|c|c|c|}
\hline \multirow{3}{*}{ Variabel } & \multicolumn{4}{|c|}{ Respon Keluarga } & \multirow{2}{*}{\multicolumn{3}{|c|}{ Nilai $\mathrm{X}^{2}$, phi, $\mathrm{p}$ value $\mathrm{CI} 95 \%$}} \\
\hline & \multicolumn{2}{|c|}{ Positif } & \multicolumn{2}{|c|}{ Negatif } & & & \\
\hline & $\mathrm{n}$ & $\%$ & $\mathrm{n}$ & $\%$ & $\mathrm{X}^{2}$ & $p h i$ & $P$ Value \\
\hline \multicolumn{8}{|l|}{ Pengetahuan } \\
\hline Baik & 7 & 16,3 & 6 & 14 & 7,467 & 0,477 & 0,006 \\
\hline Kurang & 3 & 7 & 27 & 62,8 & & & \\
\hline \multicolumn{8}{|l|}{ Struktur Keluarga } \\
\hline Baik & 8 & 18,6 & 6 & 14 & 10,356 & 0,557 & 0,001 \\
\hline Kurang & 2 & 4,7 & 27 & 62,8 & & & \\
\hline \multicolumn{8}{|l|}{ Sistem Keluarga } \\
\hline Baik & 9 & 20,9 & 5 & 11,6 & 16,321 & 0,675 & 0,000 \\
\hline Kurang & 1 & 2,3 & 28 & 65,1 & & & \\
\hline \multicolumn{8}{|c|}{ Sumberdaya Keluarga } \\
\hline Baik & 8 & 18,6 & 6 & 14 & 10,689 & 0,557 & 0,001 \\
\hline Kurang & 2 & 4,7 & 27 & 62,8 & & & \\
\hline
\end{tabular}




\section{Hubungan pengetahuan dengan respon keluarga pasien}

Sebuah keluarga dengan penderita gangguan jiwa perlu mengetahui dan menyadari keadaan diri penderita, mengambil keputusan untuk menetukan bagaimana sikap yang sebaiknya diambil agar terhindar dari hal-hal yang tidak diinginkan. Banyak keluarga yang berpendapat bahwa penderita boleh berhenti minum obat (berobat) apabila gejala-gejala sudah menghilang/berkurang, juga banyak keluarga yang berpendapat bahwa penderita gangguan jiwa hanya perlu medikasi (obat-obatan) untuk dapat sembuh saat proses pemulihannya dirumah. Hal ini jelas keliru, terapibagi penderita gangguan jiwa bukan hanya pemberian obat dan rehabilitasi medik, namun diperlukan peran keluarga guna resosialisasi dan pencegahan kekambuhan (Vijay, 2005).

Tabel 1 menunjukkan bahwa dari 43 orang responden, yang paling banyak adalah pengetahuan kurang sebanyak 30 orang $(69,8 \%)$. Hal ini disebabkan karena tingkat pendidikan responden yang rendah, yang mana dalam penelitian ini sekitar $74,4 \%$ responden memiliki tingkat pendidikan rendah yakni SD dan SMP. Menurut Lueckenotte (2000), bahwa tingkat pendidikan seseorang dapat mempengaruhi kemampuan untuk menyerap informasi, menyelesaikan masalah, dan berperilaku baik. Pendidikan rendah berisiko ketidakmampuan dalam merawat kesehatannya (WHO, 2009).

Kurangnya pengetahuan tentang kesehatan jiwa di kalangan umum memang tidak dipungkiri sebagai sebab utama terhadap perlakuan tidak adil yang diterima para penderita gangguan jiwa. Perlakuan tidak adil ini tidak hanya berakibat pada klien tetapi juga keluarganya (Smith $\&$ Casswell, 2010). Hasil analisis hubungan antara pengetahuan dengan respon keluarga pasien gangguan jiwa, diperoleh bahwa dari 43 responden yang mempunyai pengetahuan baik, lebih banyak memiliki respon keluarga positif sebanyak 7 orang $(16,3 \%)$. Pengetahuan keluarga mengenai kesehatan mental merupakan awal usaha dalam memberikan iklim yang kondusif bagi anggota kelurganya. Keluarga selain dapat meningkatkan dan mempertahankan kesehatan mental anggota keluarga, juga dapat menjadi sumber problem bagi anggota keluarga yang mengalami persoalan kejiwaan keluarganya (Notosoedirdjo \& Latipun, 2005).

Setelah dibandingkan antara kondisi anggota keluarga yang berpengetahuan baik dan yang tidak memiliki pengetahuan baik diketahui bagaimana perawatan terhadap anggota keluarganya yang mengalami gangguan jiwa, di mana kondisi keluarga yang berpengetahuan baik lebih terjaga dibandingkan pada keluarga yang tidak memiliki pengetahuan yang baik. Dengan demikian sangat diperlukan bagi keluarga untuk memiliki pengetahuan yang baik dalam menghadapi anggota keluarga yang mengalami gangguan jiwa.

Hasil uji Chi Square menunjukkan bahwa ada hubungan yang signifikan berdasarkan nilai alfa $(0,05)$ antara pengetahuan dengan respon keluarga pasien gangguan jiwa di rawat jalat RSJ Provinsi Sulawesi Tenggara tahun 2018. Artinya, semakin kurang pengetahuan keluarga terhadap kesehatan jiwa maka keluarga akan cenderung merespon negatif terhadap pasien gangguan jiwa. Hasil penelitian ini sejalan dengan penelitian yang dilakukan oleh Amalia (2013) yang menunjukkan bahwa ada hubungan signifikan antara pengetahuan keluarga dengan respon keluarga pasien gangguan jiwa di RSJ dr. Amino Gondhohutomo. Oleh karena itu, keluarga harus menambah pengetahuan dan melengkapi dirinya dengan berbagai pengetahuan dan keterampilan sehingga dapat memperlakukan mereka dalam keluarga secara baik dan memadai, bersifat terapeutik dan membawa anggota keluarga tersebut kepada kesembuhan yang seterusnya.

\section{Hubungan struktur keluarga dengan respon keluarga pasien}

Struktur keluarga meliputi pola dan proses komunikasi yang memungkinkan anggota keluarga untuk mengekspresikan marahnya, sedih, gembira, komunikasi yang terbuka, komunikasi yang dapat menyelesaikan konflik keluarga, suasana emosi yang hangat, saling percata, menghargai, memperhatikan dan menerima.

Tabel 1 menunjukkan bahwa dari 43 orang responden, yang paling banyak adalah struktur keluarga kurang sebanyak 29 orang $(67,4 \%)$. Menurut (Friedman, 2010) dukungan emosional yang diberikan keluarga, bentuk dukungan atau bantuan yang dapat memberikan rasa aman, cinta kasih, membangkitkan semangat, mengurangi 
Faletehan Health Journal, 6 (2) (2019) 69-74

www. journal.Ippm-stikesfa.ac.id/ojs/index.php/FHJ ISSN 2088-673X | 2597-8667

putus asa, rasa rendah diri, rasa keterbatasan sebagai akibat dari ketidakmampuan fisik atau kognitif, penurunan kesehatan dan kelainan yang dialaminya.

Hasil analisis hubungan antara struktur keluarga dengan respon keluarga pasien gangguan jiwa, diperoleh bahwa dari 43 responden yang mempunyai struktur keluarga baik, lebih banyak memiliki respon keluarga positif sebanyak 8 orang $(18,6 \%)$. Keluarga juga harus lebih terbuka dan memahami serta menghargai perasaan klien, mendengarkan keluhan-keluhan yang disampaikan klien, menanyakan apa yang saat ini klien rasakan, ini merupakan salah satu bentuk dukungan dari keluarga secara psikis.

Hasil uji Chi Square menunjukkan bahwa ada hubungan yang signifikan berdasarkan nilai alfa $(0,05)$ antara struktur keluarga dengan respon keluarga pasien gangguan jiwa di Ruang Rawat Jalan RSJ Provinsi Sulawesi Tenggara tahun 2018. Artinya,semakin kurang struktur keluarga terhadap kesehatan jiwa maka keluarga akan cenderung merespon negatif terhadap pasien gangguan jiwa. Hasil penelitian ini sejalan dengan penelitian yang dilakukan oleh Amalia(2013) yang menunjukkan bahwa ada hubungan signifikan antara struktur keluarga dengan respon keluarga pasien gangguan jiwa di RSJ dr. Amino Gondhohutomo.

\section{Hubungan sistem keluarga dengan respon keluarga pasien}

Keluarga sebagai sebuah kelompok yang dapat menimbulkan, mencegah atau memperbaiki masalah kesehatan yang dalam hal ini adalah gangguan jiwa yang ada dalam kelompoknya sendiri, oleh karena itu keluarga merupakan sistem yang terutama sebagai pendukung bagi klien setelah pulang dari rumah sakit jiwa. Maka dukungan keluarga dan lingkungan menjadi faktor yang penting.

Dari 43 orang responden, yang paling banyak adalah sistem keluarga kurang sebanyak 29 orang $(67,4 \%)$. Penderita gangguan jiwa sangat membutuhkan dukungan, kasih sayang, dan perhatian khususnya dari keluarga, hal ini dapat ditunjukkan dari keikutsertaan keluarga dalam membantu perawatan pada penderita gangguan jiwa. Perawatan tersebut dapat memberikan perawatan secara fisik maupun secara psikis karena banyaknya stigma buruk berkembang di masyarakat terhadap penderita gangguan jiwa, sehingga dengan adanya dukungan, kasih sayang serta perawatan yang baik tersebut akan membantu mempercepat kesembuhan pasien.

Hasil uji Chi Square menunjukkan bahwa ada hubungan yang signifikan berdasarkan nilai alfa $(0,05)$ antara sistem keluarga dengan respon keluarga pasien gangguan jiwa di Ruang Rawat Jalan RSJ Provinsi Sulawesi Tenggara tahun 2018. Artinya, semakin kurang sistem keluarga terhadap kesehatan jiwa maka keluarga akan cenderung merespon negatif terhadap pasien gangguan jiwa. Hasil penelitian ini sejalan dengan penelitian yang dilakukan oleh Amalia (2013) yang menunjukkan bahwa ada hubungan signifikan antara sistem keluarga dengan respon keluarga pasien gangguan jiwa di RSJ dr. Amino Gondhohutomo.

\section{Hubungan sumber daya keluarga dengan respon keluarga pasien}

Berdasarkan hasil penelitian diketahui bahwa dari 43 orang responden, yang paling banyak adalah sumber daya keluarga kurang sebanyak 29 orang $(67,4 \%)$. Banyak hal yang tidak dilakukan keluarga dalam menjalankan tugasnya sebagai keluarga yang merawat anggot keluarga yang sakit jiwa. Hal-hal yang dapat dilakukan keluarga dalam merawat penderita gangguan jiwa diantaranya mengawasi klien dalam meminum obat secara teratur hingga klien menelan obatnya. Klien harus meminum obatnya pada pagi hari karena obat tersebut paling baik bekerja ketika pagi hari, keluarga juga harus dapat memotivasi pasien agar sabar dalam pengobatannya, menempatkan obat di tempat yang bersih dan kering, tidak terpapar langsung dengan sinar matahari dan aman dari jangkauan anak-anak, selain itu keluarga dapat membawa atau mengajak pasien ke fasilitas kesehatan setiap dua minggu sekali untuk melihat perkembangan penyakitnya atau jika pasien mengalami keluhan-keluhan yang harus segera ditangani.

Hasil analisis hubungan antara sumber daya keluarga dengan respon keluarga pasien gangguan jiwa, diperoleh bahwa dari 43 responden yang mempunyai sumber daya keluarga baik, lebih banyak memiliki respon keluarga positif sebanyak 8 orang $(18,6 \%)$. Penghasilan keluarga merupakan salah satu wujud dari dukungan intrumental yang akan digunakan dalam mencari pelayanan kesehatan jiwa dalam merawat anggota keluarga dengan gangguan jiwa.Faktor sosial ekonomi 
disini meliputi tingkat pendapatan atau penghasilan keluarga klien, semakin tinggi tingkat ekonomi keluarga akan lebih memberikan dukungan dan pengambilan keputusan dalam merawat anggota klien gangguan jiwa. Keluarga dengan kelassosial ekonomi yang berlebih secara finansial akan mempunyai tingkat dukungan keluarga yang memadai.

Hasil uji Chi Square menunjukkan bahwa ada hubungan yang signifikan antara sumber daya keluarga dengan respon keluarga pasien gangguan jiwa di Ruang Rawat Jalan RSJ Provinsi Sulawesi Tenggara tahun 2018. Artinya,semakin kurang sumber daya keluarga terhadap kesehatan jiwa maka keluarga akan cenderung merespon negatif terhadap pasien gangguan jiwa. Hasil penelitian ini sejalan dengan penelitian yang dilakukan oleh Amalia (2013) yang menunjukkan bahwa ada hubungan signifikan antara sumber daya keluarga dengan respon keluarga pasien gangguan jiwa di RSJ dr. Amino Gondhohutomo.

\section{Simpulan}

Berdasarkan hasil penelitian dapat disimpulkan bahwa respon keluarga terhadap penderita gangguan jiwa berhubungan dengan pengetahuan, struktur keluarga, system pendukung dan sumber daya keluarga.

\section{Referensi}

Amalia, (2013), Kesiapan Keluarga Menghadapi Kepulangan Pasien Rawat Inap Gangguan Jiwa di Rumah Sakit Jiwa dr. Amino Gondhohutomo. Skripsi. Fakultas Ilmu Pendidikan Universitas Negeri Semarang

Basford, L, (2006),Teori dan Praktik Keperawatan : Pendekatan Integral pada Asuhan Pasien, Jakarta: EGC.

Depkes RI,(2007), Laporan Hasil Riset Kesehatan Dasar (RISKESDAS) Nasional 2007, Badan
Penelitian dan Pengembangan Depkes RI, Jakarta.

Kartiko, (2009), Hubungan Pengetahuan tentang Gangguan Jiwa dan Dukungan Keluarga yang Mempunyai Anggota Keluarga Skizofrenia di RSJD Surakarta. Skripsi Fakultas Ilmu Kesehatan Universitas Muhammadiyah Surakarta

Lueckenotte, A.G, (2000), Gerontologic Nursing. (2nd ed.), Missouri: Mosby.

Notosoedirdjo \& Latipun, (2005), Kesehatan Mental, Konsep dan Penerapan, Jakarta: EGC

Priyanto, (2007), http://ebookdatabase.net/apakahgangguan-jiwa-itu-59070351. Diakses pada tanggal 10 Januari 2018.

Smith, A \& Casswell. C, (2010), Stigma and Mental Illness : Investigating Attitudes of Mental Health and Non-Mental Health Professionals and Trainees, Journal of Humanistic Counselling, Education and Development, vol. 49, no. 2

Suliswati, (2005), Konsep dasar keperawatan jiwa, Jakarta: EGC.

Vijay \& Chandra, (2005), Cara Pencegahan dan Pengobatan Gangguan Jiwa. http://www.BaliPost.co.id. 3 Agustus 2005. Diakses 20 Januari 2018

WHO, (2009), Improving Health System and Service for Mental Health: WHO Library Cataloguing-in- Publication Data

Yosep, I, (2007),Mencegah Gangguan Jiwa Mulai Dari Keluarga. http://ebookbrowse.com/mencegahgangguan-jiwa-mulaidari-keluarga-kitapdfd14398638. Di akses pada tanggal 21 Januari 2018

Yosep. I, (2010), Keperawatan Jiwa, Ed. Revisi. Cet. Ke-3. Bandung: PT. Refika Aditama. 